\title{
Review
}

\section{Roles of Sulfated Glycans in Lymphocyte Homing}

\author{
Hiroto KAWASHIMA \\ Department of Microbiology, School of Pharmaceutical Sciences, University of Shizuoka; \\ 52-1 Yada, Shizuoka 422-8526, Japan. \\ Received August 31, 2006
}

\begin{abstract}
Lymphocyte homing is mediated by a specific interaction between the lymphocyte homing receptor L-selectin and its sulfated glycoprotein ligands, which are expressed on high endothelial venules (HEV) in the lymph nodes. To examine the significance of the sulfation of L-selectin ligands, our group has generated gene-targeted mice deficient in both $\mathrm{N}$-acetylglucosamine-6- $\mathrm{O}$-sulfotransferase (GIcNAc6ST)-1 and GIcNAc6ST-2. The mutant mice show approximately $\mathbf{7 5 \%}$ less lymphocyte homing to the peripheral lymph nodes than normal, indicating that GlcNAc6ST-1 and GlcNAc6ST-2 play a major role in the biosynthesis of L-selectin ligand in HEV. In agreement with this interpretation, an oligosaccharide analysis indicated that 6-sulfo sialyl Lewis $\mathrm{X}$, a major L-selectin ligand sulfated glycan, is almost completely abrogated in the double-deficient mice. Lymphocyte homing into the parenchyma of lymph nodes is mediated by a series of interactions: rolling, activation by chemokines, integrin-mediated adhesion, and transmigration. During the rolling interaction, which is mediated by L-selectin and sulfated glycans, lymphocytes receive activation signals from chemokines presented on the surface of HEV by heparan sulfate, a sulfated glycosaminoglycan, which leads to the activation of lymphocyte $\beta 2$ integrin. Sulfated glycans are thus involved in both the rolling and the chemokine-induced activation steps between lymphocytes and HEV. In this article, recent findings on the roles of sulfated glycans in both of these lymphocyte-homing steps will be reviewed. The possible application of sulfated glycans for the prevention of inflammatory disorders will also be discussed.
\end{abstract}

Key words L-selectin; sulfotransferase; high endothelial venule; lymphocyte homing; heparan sulfate; chondroitin sulfate

\section{LYMPHOCYTE HOMING}

Lymphocytes are generated in primary lymphoid organs, such as the bone marrow and thymus, and migrate to the lymph nodes, Peyer's patches, and spleen, known as secondary lymphoid organs, where the immune responses occur. Lymphocytes that migrate to the lymph nodes and Peyer's patches emigrate through the efferent lymph, unless they encounter their cognate antigens. Lymphocytes that emigrate through the lymph return to the bloodstream through the thoracic duct, through which lymph fluid drains into the blood. Lymphocytes that return to the blood migrate again into the secondary lymphoid organs. This circulatory process is called lymphocyte recirculation or lymphocyte homing. Antigens that enter the body from peripheral tissues such as the skin accumulate in the lymph nodes. Antigens in the blood are collected in the spleen. Those in food are taken up by M cells residing in the mucosal intestinal epithelial barrier and accumulate in the Peyer's patches. Thus, the secondary lymphoid organs are the sites where foreign antigens accumulate and immune responses primarily occur. The homing of lymphocytes into secondary lymphoid organs through the blood and lymph circulation raises the likelihood that lymphocytes will encounter antigens. In other words, lymphocyte homing is important for the immune system to recognize foreign antigens efficiently.

Lymphocytes migrate into the parenchyma of lymph nodes through specialized blood vessels called high endothelial venules (HEV). HEV have a characteristic cuboidal morphology and a prominent Golgi complex where unique sulfated glycans are synthesized, as discussed later. Lymphocyte migration is achieved by a series of interactions between lymphocytes and $\mathrm{HEV}^{1)}$ (Fig. 1): (i) the rolling of lymphocytes, which is mediated by L-selectin on the lymphocytes and sulfated glycans on the HEV; (ii) activation of the lymphocytes by chemokines presented on the surface of the HEV by heparan sulfate, a glycosaminoglycan; (iii) firm attachment of the lymphocytes through the interaction between $\beta 2$ integrins on the lymphocytes and intercellular adhesion molecule-1 (ICAM-1) or vascular cell adhesion molecule-1 (VCAM-1) on the HEV; and (iv) transmigration.

\section{HOMING RECEPTOR L-SELECTIN}

The homing receptor L-selectin (LECAM-1, CD62L, LAM-1) was first identified as an antigen recognized by the monoclonal antibody (mAb) MEL-14, which blocks the binding of lymphocytes to HEV in vitro and in vivo. L-selectin is an adhesion molecule that recognizes carbohydrates through a lectin-like domain in its N-terminus, through which it mediates the initial tethering and rolling of lymphocytes on the surface of HEV. L-selectin is localized to the tips of microvilli, ${ }^{2}$ which is advantageous for the initial tethering to HEV-borne carbohydrate ligands. To date, several kinds of glycoprotein ligands for L-selectin have been identified (see below).

L-selectin is expressed not only on lymphocytes, but also on other types of leukocytes, such as neutrophils and monocytes. L-selectin is involved in the infiltration of these leukocyte subsets into sites of inflammation, which can be inhibited by an anti-L-selectin mAb or by low-molecular-size compounds that block L-selectin's carbohydrate-binding activity. This role of L-selectin has been verified by studies using L-selectin-deficient mice, which show not only an almost complete lack of lymphocyte trafficking to the peripheral lymph nodes, but also a significant reduction of leukocyte infiltration into inflammatory sites. ${ }^{3)}$ 


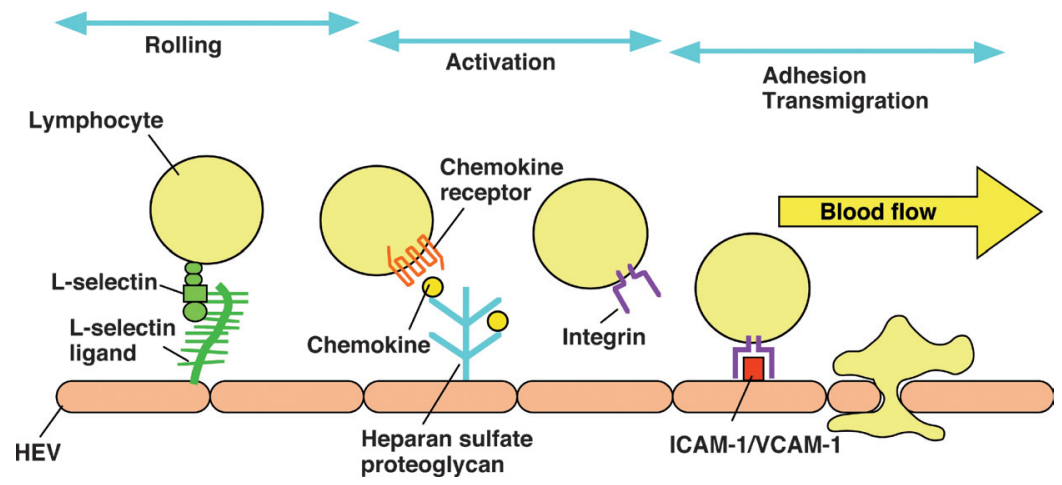

Fig. 1. Multi-Step Model for Lymphocyte Interaction with HEV

Lymphocytes initiate the interaction with HEV by L-selectin binding to its ligand, followed by chemokine-induced activation, integrin-mediated adhesion and transmigration. Sulfated glycans function in the first and second steps of these sequential adhesive interactions.

\section{LIGANDS FOR L-SELECTIN}

Studies of the carbohydrate-based ligands for L-selectin that are expressed on the lymph node HEV have identified various sialomucins, such as GlyCAM- $1,{ }^{4)} \mathrm{CD} 34,{ }^{5)}$ podocalyxin-like protein, ${ }^{6}$ Sgp $200,{ }^{7}$ and nepmucin. ${ }^{8)}$ The binding of these glycoprotein ligands to L-selectin is dependent on their decoration with a specific carbohydrate structure known as 6-sulfo sialyl Lewis X (Sialic acid $\alpha 2-3 \mathrm{Gal} \beta 1-4[$ Fuc $\alpha 1$ 3(sulfo-6)]GlcNAc $\beta 1-\mathrm{R}$ ), which contains sialic acid, fucose, and sulfate (Fig. 2). The 6-sulfo sialyl Lewis $\mathrm{X}$ structure is present in either the core 2 or extended core 1 branch, or both, of the L-selectin ligand $O$-glycans. ${ }^{9)}$ The same study revealed that the MECA-79 antibody, which is widely used to detect HEV in lymph nodes or HEV-like vessels at the sites of chronic inflammation, ${ }^{10)}$ recognizes $O$-glycans containing 6-sulfo $\mathrm{N}$-acetylglucosamine in the extended core 1 structure.

Earlier studies by Dr. Rosen's group showed that sialic acid is critical for the interaction of HEV ligands with lymphocytes. ${ }^{11)}$ Studies using gene-targeted mice deficient in fucosyltransferase IV and VII revealed that the fucosylation of HEV ligands is also critical for their interaction with L-selectin. ${ }^{12)}$ In vitro biochemical studies showed that the sulfation of L-selectin ligands is also important for their interaction with L-selectin, since GlyCAM-1 synthesized in the presence of sodium chlorate, which inhibits biosynthesis of the high-energy donor of sulfate, $3^{\prime}$-phosphoadenosine $5^{\prime}$ phosphosulfate (PAPS), did not interact with L-selectin. ${ }^{13)}$

\section{ROLES OF L-SELECTIN LIGAND SULFATION IN VIVO}

To determine the sulfation requirement of the L-selectin ligands in vivo, mice deficient in the HEV-restricted sulfotransferase, $\quad N$-acetylglucosamine-6- $O$-sulfotransferase-2 (GlcNAc6ST-2, HEC-GlcNAc6ST/LSST) ${ }^{14,15)}$ were generated. In the GlcNAc6ST-2 knockout mice, binding of the MECA-79 antibody to lymph node HEV was almost abolished, except for binding observed in the abluminal lining of the HEV, suggesting that GlcNAc-6-O-sulfation in the extended core 1 branch is mediated mainly by GlcNAc6ST-2.

In mice, four members of the GlcNAc-6-O-sulfotransferase family have been reported (Table 1). One of these, GlcNAc6ST-1, is widely expressed in various tissues, includ-
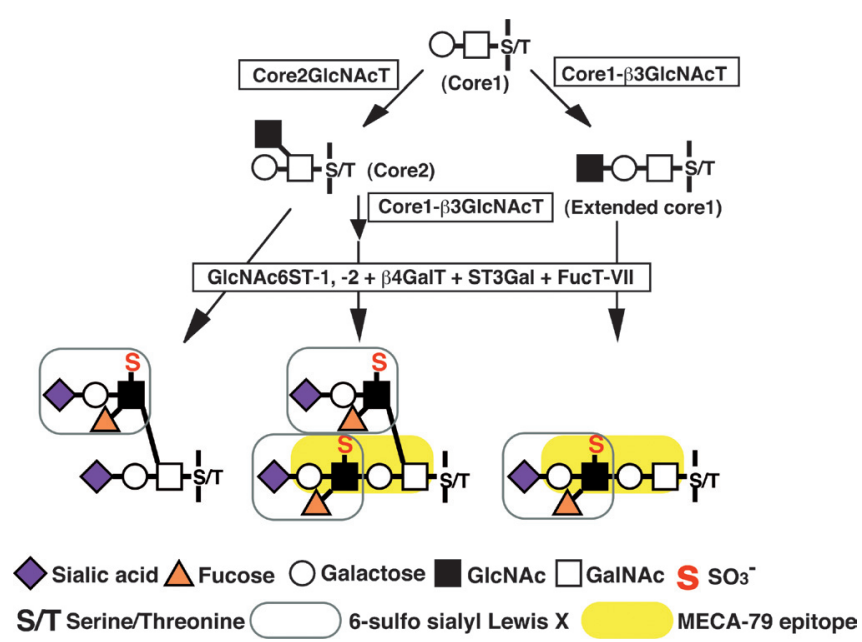

Fig. 2. Biosynthesis of the L-Selectin Ligand $O$-Glycans

Core 2 branched $O$-glycan (left), extended core 1 structure (right), and biantennary $O$-glycan containing both core 2 branch and extended core 1 structures (middle) modified with 6-sulfo sialyl Lewis X (outlined in gray) are synthesized in HEV by the sequential addition of monosaccharides and sulfate. The extended core 1 structure modified with GlcNAc-6- $O$-sulfate (shown in yellow) is recognized by the MECA-79 antibody. Core2GlcNAcT, Core $2 \beta 1,6-N$-acetylglucosaminyltransferase; Core $1-\beta 3 \mathrm{GlcN}$ AcT, Core 1 extension $\beta 1,3-N$-acetylglucosaminyltransferase, GlcNAc6ST-1, $-2, N$ acetylglucosamine-6- $O$-sulfotransferase-1, $\quad-2 ; \quad \beta 4 \mathrm{GalT}, \quad \beta 1$,4-galactosyltransferase; ST3Gal, $\alpha 2,3$-sialyltransferase; FucT-VII, fucosyltransferase-VII

ing lymph node HEV. Our group ${ }^{16)}$ and others ${ }^{17)}$ therefore crossbred GlcNAc6ST-2-deficient mice with GlcNAc6ST-1deficient mice to determine whether GlcNAc6ST-1 and GlcNAc6ST-2 had complementary roles in L-selectin ligand biosynthesis. Immunofluorescence studies revealed that the binding of the MECA-79 antibody to the lymph node HEV of the double-deficient mice was completely abrogated, indicating that GlcNAc-6-O-sulfation in the extended core 1 branch of $O$-glycans in HEV was absent in the double-deficient mice (Fig. 3). While GlcNAc6ST-1 and GlcNAc6ST-2 single-deficient mice showed an approximately $20 \%$ and $50 \%$ reduction in lymphocyte homing, respectively, GlcNAc6ST-1 and GlcNAc6ST-2 double-deficient mice showed an approximately $75 \%$ reduction in lymphocyte homing. ${ }^{16,17)}$ The contact hypersensitivity (CHS) responses were also significantly diminished in the double-deficient mice, due to a reduction in lymphocyte trafficking to the draining lymph nodes. ${ }^{16)}$ These results demonstrate the essential role of GlcNAc6ST-1 and GlcNAc6ST-2 in L-selectin ligand biosynthe- 
Table 1. Mouse $\mathrm{N}$-Acetylglucosamine-6-O-sulfotransferases

\begin{tabular}{|c|c|c|c|c|}
\hline Name & Other names & $\begin{array}{c}\text { cDNA accession } \\
\text { number }\end{array}$ & $\begin{array}{c}\text { Tissue } \\
\text { distribution }\end{array}$ & Function etc. \\
\hline GlcNAc6ST-1 & $\begin{array}{l}\text { GlcNAc6ST } \\
\text { CHST (carbohydrate sulfotransferase)-2 } \\
\text { GST (galactose } / N \text {-acetylgalactosamine/ } \\
N \text {-acetylglucosamine 6-O- } \\
\text { sulfotransferase)-2 }\end{array}$ & AB011451 & $\begin{array}{l}\text { Various tissues } \\
\text { including HEV }\end{array}$ & $\begin{array}{l}\text { In GlcNAc6ST-1-deficient mice, } \\
\text { lymphocyte homing to PLN was reduced } \\
\text { by } 20 \%{ }^{18)} \text { In these mice, the binding of } \\
\text { MECA-79 to the HEV of PP disappeared. }\end{array}$ \\
\hline GlcNAc6ST-2 & $\begin{array}{l}\text { LSST (L-selectin ligand sulfotransferase) } \\
\text { HEC-GlcNAc6ST (high endothelial cell } \\
\quad N \text {-acetylglucosamine 6-sulfotransferase) } \\
\text { CHST-4 } \\
\text { GST-3 }\end{array}$ & AF109155 & HEV-specific & $\begin{array}{l}\text { In GlcNAc6ST-2-deficient mice, } \\
\text { lymphocyte homing to PLN was 50\% } \\
\text { reduced. }{ }^{14,15)} \text { In these mice, luminal staining } \\
\text { of PLN HEV with MECA-79 disappeared. }\end{array}$ \\
\hline GlcNAc6ST-3 & $\begin{array}{l}\text { I-GlcNAc6ST (intestinal } N \text { - } \\
\quad \text { acetylglucosamine } 6 \text { - } O \text {-sulfotransferase) } \\
\text { CHST-5 } \\
\text { GST-4 }\end{array}$ & AF 176840 & Intestine, cornea & $\begin{array}{l}\text { In mice, only I (Intestinal)-GlcNAc6ST } \\
\text { (GlcNAc6ST-3, CHST-5) is present. } \\
\text { In humans, I-GlcNAc6ST (GlcNAc6ST-3, } \\
\text { CHST-5, and GST-4 } \alpha \text { ) and C (Corneal)- } \\
\text { GlcNAc6ST (GlcNAc6ST-5, CHST-6, and } \\
\text { GST-4 } \beta \text { ) are present because of gene } \\
\text { duplication. }\end{array}$ \\
\hline GlcNAc6ST-4 & $\begin{array}{l}\text { C6ST (chondroitin 6-sulfotransferase)-2 } \\
\text { CHST-7 } \\
\text { GST-5 }\end{array}$ & AF280089 & $\begin{array}{l}\text { Various tissues } \\
\text { including } \mathrm{HEV}^{16)}\end{array}$ & $\begin{array}{l}\text { GlcNAc6ST- } 4 \text { transfers sulfate to } \\
\text { recombinant GlyCAM-1-IgG. }{ }^{56)} \text { In vivo } \\
\text { function of GlcNAc6ST-4 is unknown. }\end{array}$ \\
\hline
\end{tabular}
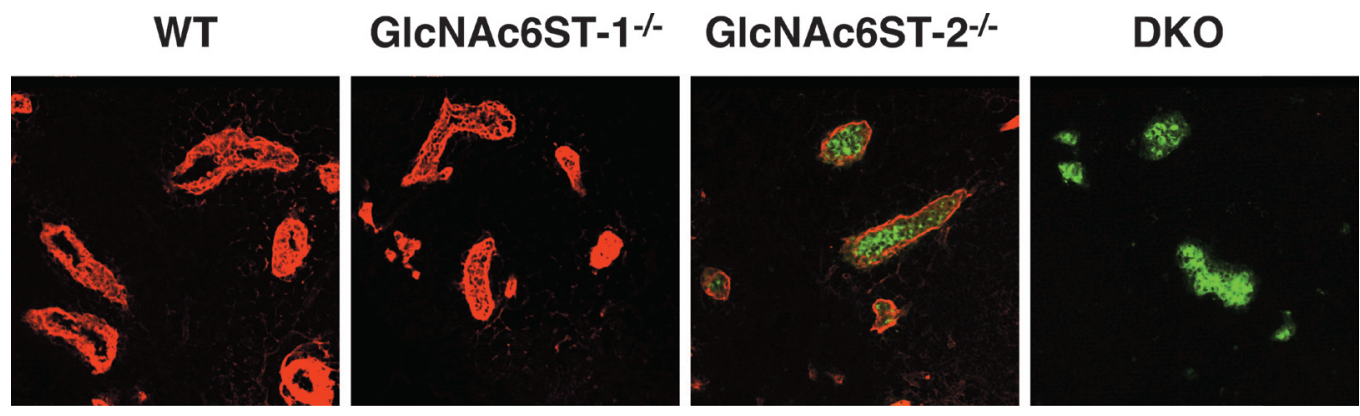

Fig. 3. Immunofluorescence

Frozen sections of peripheral lymph nodes from wild-type and mutant mice were stained with the MECA-79 antibody (red). Green fluorescence is from the knocked-in GlcNAc6ST-2-EGFP chimeric protein.

sis in HEV and their importance in immune surveillance.

We then carried out a detailed carbohydrate structural analysis of GlyCAM-1 ${ }^{16)}$ Lymph nodes from wild-type and knockout mice were radiolabeled with $\left[{ }^{3} \mathrm{H}\right]$-galactose in organ culture, and then the $O$-glycans on GlyCAM-1 were released and subjected to structural analysis. As shown in Fig. 4, the 6-sulfo sialyl Lewis X structure was almost completely abrogated, whereas unsulfated sialyl Lewis $\mathrm{X}$ was overexpressed in the double-deficient mice.

To determine which sulfotransferases are involved in the biosynthesis of sulfated $O$-glycans in $\mathrm{HEV}$, we performed RT-PCR analysis using total RNA from the peripheral lymph node (PLN) HEV cells of wild-type mice, prepared by MACS (magnetic activated cell sorter) using the MECA-79 antibody. In addition to GlcNAc6ST-1 and -2, GlcNAc6ST-4 was detected, whereas GlcNAc6ST-3 expression was not detectable in the HEV preparation. All these mouse GlcNAc6STs efficiently transferred sulfate to core 2 branched $O$-glycans. Only GlcNAc6ST-2 and -3 efficiently transferred sulfate to extended core $1 O$-glycans, which resulted in the generation of a large amount of MECA-79 epitope (Fig. 5). GlcNAc6ST-4 did not synthesize detectable amounts of MECA-79 epitope, consistent with the finding that the

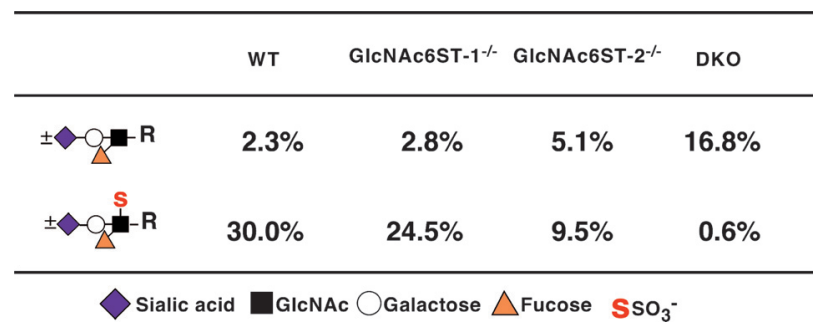

Fig. 4. Structures of the $O$-Glycans Attached to GlyCAM-1

The percentages of $O$-glycans attached to GlyCAM- 1 containing unsulfated sialyl Lewis X and 6-sulfo sialyl Lewis X are shown. Total $O$-glycans attached to GlyCAM$1=100 \%$.

MECA-79 epitope was abrogated in the GlcNAc6ST-1 and -2 double-deficient mice. The small amount of core 2 branched $O$-glycans containing GlcNAc-6- $O$-sulfate identified in the GlcNAc6ST-1 and -2 double-deficient mice was probably synthesized by GlcNAc6ST-4.

Although both GlcNAc6ST-1 and GlcNAc6ST-2 are involved in the GlcNAc-6-O-sulfation of L-selectin ligands, GlcNAc6ST-2 appears to be the major GlcNAc-6-O-sulfotransferase in PLN and mesenteric lymph nodes (MLN), because the production of 6-sulfo sialyl Lewis X-containing $O$ glycans was more diminished in the GlcNAc6ST-2-deficient 
mice than in the GlcNAc6ST-1-deficient mice (Fig. 4). In contrast, GlcNAc6ST-1 appears to be the major GlcNAc-6$O$-sulfotransferase in Peyer's patches (PP), since the MECA79 antibody staining in PP was abrogated in the absence of GlcNAc6ST-1. ${ }^{18)}$

\section{ROLES OF CHEMOKINES IN LYMPHOCYTE HOMING}

As described above, lymphocytes migrate to the parenchyma of lymph nodes through a multi-step process that mediates sequential adhesive interactions with $\mathrm{HEV}$ (Fig. 1). In these interactions, chemokines are important for the activation of the lymphocytes, resulting in integrin activation and the subsequent firm attachment of lymphocytes to HEV. Only lymphocytes but not the other leukocyte subsets can transmigrate across the HEV, and the reason for this is becoming clear. Warnock et al. showed by intravital microscopic observations that both lymphocytes and granulocytes can roll on the surface of HEV, whereas only lymphocytes can firmly attach to the HEV surface. ${ }^{19)}$ The firm attachment was mainly mediated by $\beta 2$ integrin and was blocked by pertussis toxin, which inhibits chemokine signaling by catalyzing ADP-ribosylation of the Gi subunit of seven-transmembrane chemokine receptors. Thus, lymphocyte-specific transmigration across the HEV is most likely due to chemokine signals transmitted specifically to lymphocytes on the surface of the HEV. Secondary lymphoid-tissue chemokine (SLC), which is expressed abundantly on HEV, is known to activate

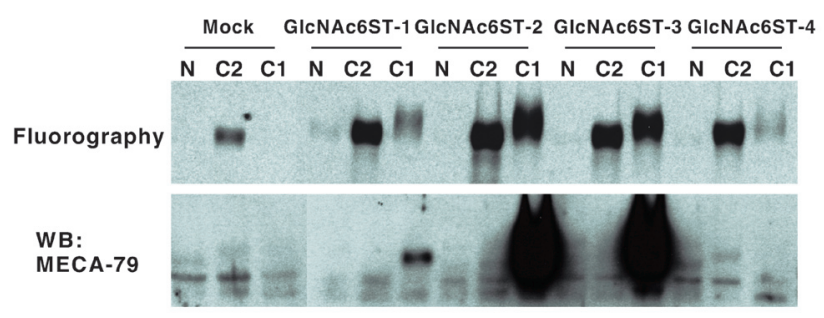

\begin{tabular}{lcccc}
\hline & GIcNAc6ST-1 & GlcNAc6ST-2 & GlcNAc6ST-3 & GIcNAc6ST-4 \\
\hline $\begin{array}{l}\text { Substrate } \\
\quad\end{array}$ & ++ & +++ & ++ & +++ \\
$\begin{array}{l}\text { Extended core 1 } \\
\text { Extende }\end{array}$ & + & +++ & +++ & \pm \\
\hline $\begin{array}{l}\text { MECA-79 epitope } \\
\text { synthesis }\end{array}$ & + & ++++ & +++ & - \\
\hline
\end{tabular}

Fig. 5. Substrate Specificity of Mouse GlcNAc6STs

Lec 2 cells were transiently transfected with expression vectors encoding GlyCAM-1$\mathrm{IgG}$, with or without $(\mathrm{N})$ Core2GlcNAcT-I (C2) or Core $1-\beta 3 \mathrm{GlcNAcT}(\mathrm{C} 1)$, together with GlcNAc6ST-1 to -4 , and metabolically labeled with $\left[{ }^{35} \mathrm{~S}\right]-\mathrm{Na}_{2} \mathrm{SO}_{4}$. GlyCAM-1-IgG was purified with protein A-Sepharose and subjected to fluorography and Western blotting using the MECA-79 antibody.

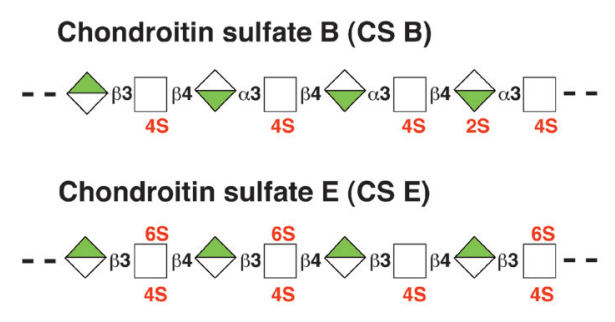

the $\beta 2$ integrin on naive lymphocytes. ${ }^{20)}$ Since the receptor for SLC, CCR7, is specifically expressed on lymphocytes but not on other leukocyte subsets, it is likely that SLC mediates, at least in part, the lymphocyte-specific trafficking to lymph nodes. Consistent with this idea, mutant mice that are defective in T lymphocyte homing to lymph nodes, called "paucity of lymph node T cells" (plt) mice, are deficient in secondary lymphoid organ-specific SLC gene and in another gene, which encodes EBI1-ligand chemokine (ELC), a chemokine that transmits signals through CCR7. ${ }^{21,22)}$ In addition, lymphocyte homing and secondary lymphoid organ development are greatly diminished in CCR7-deficient mice. ${ }^{23)}$

\section{PRESENTATION OF CHEMOKINES BY GLYCO- SAMINOGLYCANS}

Chemokines are soluble basic proteins with molecular sizes ranging from 8 to $12 \mathrm{kDa}$. The sequestration and presentation of chemokines by glycosaminoglycans, sulfated glycans attached to proteoglycans, appear to be important for preventing the rapid removal of chemokines from the surface of HEV by the blood flow. Sulfated glycans are thus very likely to be involved not only in the L-selectin-mediated rolling but also in the chemokine-mediated activation in the series of interactions between lymphocytes and HEV.

Glycosaminoglycans that are known to interact with chemokines are shown in Fig. 6. Heparan sulfate proteoglycans (HSPG), which are modified with heparan sulfate (HS) glycosaminoglycans, are present in the extracellular matrix and on the surface of cells, and are known to interact with various growth factors. ${ }^{24)}$ For example, basic fibroblast growth factor (bFGF) is sequestered by HSPG, which is a low-affinity receptor, and then passed to the high-affinity FGF receptor, which transmits intracellular signals. In an analogy to this, HSPG appear to be involved in chemokine immobilization and presentation to the receptor. It is reported that MIP-1 $\beta$ sequestered on CD44 modified with HS or heparin-bovine serum albumin (BSA) efficiently activates the VLA-4 integrin of $\mathrm{CD}^{+} \mathrm{T}$ cells, and promotes their firm attachment to VCAM-1. ${ }^{25)}$ HSPG expressed on endothelial cells derived from the synovium of rheumatoid arthritis patients present MIP-1 $\beta$ to lymphocytes, leading to their integrin activation. ${ }^{26)}$ In addition, a study using extracellular matrices from bovine endothelial cells showed that, when bound to HSPG, the chemokines RANTES and MIP- $1 \beta$ efficiently enhanced the attachment of $\mathrm{CD}^{+}{ }^{+} \mathrm{T}$ cells to the ECM. ${ }^{27}$ ) HSPG on the surface of adult T-cell leukemia (ATL) cells present MIP-1 $\beta$ produced by themselves to their own chemokine receptors, which results in the constitutive activa-

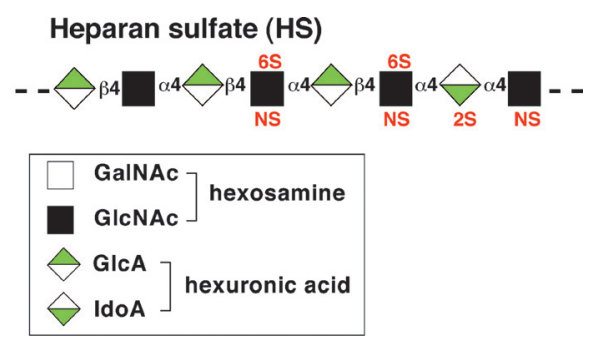

Fig. 6. Structures of Chemokine-Binding Glycosaminoglycans

$2 S$, 2- $O$-sulfation; $4 S$, 4- $O$-sulfation; $6 S, 6-O$-sulfation; $N S, N$-sulfation; $\alpha 3, \alpha 1$-3 linkage; $\alpha 4, \alpha 1$-4 linkage $\beta 3$, $\beta 1$-3 linkage; $\beta 4, \beta 1$-4 linkage. 


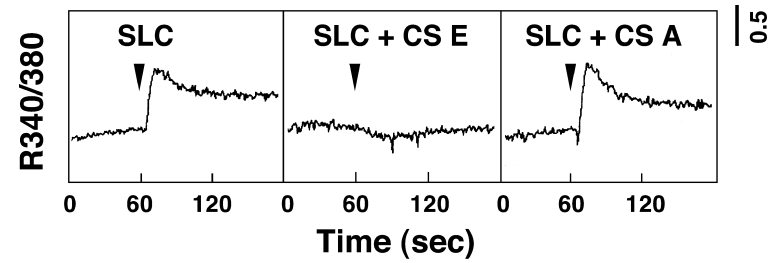

Fig. 7. CS E Inhibits the $\mathrm{Ca}^{2+}$ Influx induced by SLC

L1.2 cells expressing CCR7 were loaded with Fura-2 and stimulated with SLC in the presence or absence of CS E or CS A. Arrowheads indicate the time stimulators were added. Emission fluorescence intensity at $510 \mathrm{~nm}$ was measured upon excitation at $340 \mathrm{~nm}$ (F340) and $380 \mathrm{~nm}$ (F380). Data are presented as the ratio of F340 divided by F380 (R340/380), which reflects the intracellular calcium concentration. The scale is shown as a bar on the right.

tion of their integrins. ${ }^{28)}$ Our group also reported that collagen XVIII expressed in the kidney is modified with HS and efficiently presents the chemokine MCP-1 to monocytes, thereby enhancing their VLA-4 integrin activation. ${ }^{29)} \mathrm{Re}$ cently, Esko's group reported that endothelial cell-specific gene inactivation of $N$-deacetylase- $N$-sulfotransferase-1 (NDST-1), which is involved in the $N$-deacetylation and $N$ sulfation of HS in its biosynthetic pathway, resulted in a significant reduction in chemokine-mediated neutrophil trafficking to sites of inflammation. ${ }^{30)}$ Although they did not provide any data on the roles of HS in chemokine presentation on $\mathrm{HEV}$, it is likely that HS also at least partly plays this role in vivo.

Proteoglycans modified with chondroitin sulfate (CS) chains are called chondroitinsulfate proteoglycans (CSPG), and are reported to interact with chemokines. The chemokine RANTES interacts with CSPG on the cell surface of macrophages. ${ }^{31)}$ RANTES also interacts with an artificial CSPG composed of lymphocyte function-associated antigen3 (LFA-3) fused with the CS-attachment domain of CD44. ${ }^{32)}$ Our group showed that the chemokine SLC interacts with oversulfated CS with relatively high affinity $\left(K_{d} 85.8 \mathrm{nM}\right)$, and that the minimum carbohydrate structure that interacts with SLC is a tetrasaccharide composed of a repeated disaccharide unit (GlcA $\beta 1 / \operatorname{IdoA} \alpha 1$-3GalNAc[4,6-O-disulfate]). ${ }^{33)}$ We also showed, using a cell line expressing CCR7, that an oversulfated $\mathrm{CS}, \mathrm{CS} \mathrm{E}$, interacts with the $\mathrm{C}$-terminal region of SLC and inhibits SLC-induced $\mathrm{Ca}^{2+}$ influx (Fig. 7). ${ }^{33,34)}$ In addition, we found that $\mathrm{CS} B$ has inhibitory effects on the SLC-induced $\mathrm{Ca}^{2+}$ influx. ${ }^{35)}$ On the other hand, HS interacts with chemokines, but presents them positively to lymphocytes, leading to chemokine-induced lymphocyte activation. Thus, CS B and CS E appear to function as negative regulators of chemokine signals, whereas HS functions to stimulate chemokine signals (Fig. 8). This might be of physiological importance in the regulation of chemokine activity in vivo.

\section{TRAFFICKING OF ACTIVATED LYMPHOCYTES}

As described above, naive lymphocytes continuously home to lymph nodes until they encounter their cognate antigens. Once they encounter the antigens, they are activated and show a different expression pattern of adhesion molecules, resulting in different homing patterns compared with naive lymphocytes. Activated lymphocytes lose their expression of L-selectin, and some express cutaneous lymphocyte antigen

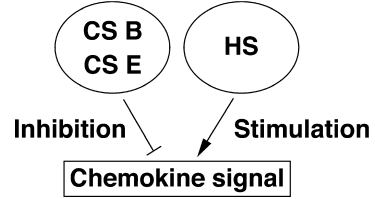

Fig. 8. Effects of Glycosaminoglycans on Chemokine Signals CS B and CS E inhibit chemokine signals, whereas HS stimulates them.

(CLA), which is reactive with the HECA-452 mAb. These HECA-452-reactive activated lymphocytes specifically home to inflammatory sites where antigens enter, which is consistent with the expression of E-selectin on the activated endothelial cells in inflamed tissue. Molecular characterization revealed that CLA is a P-selectin glycoprotein-1 (PSGL-1) modified with the sialyl Lewis $\mathrm{X}$ structure. ${ }^{36)}$ In agreement with this finding, interleukin-12, which activates naive $\mathrm{T}$ cells and stimulates the generation of Th1 cells, induces the expression of fucosyltransferase VII, a key glycosyltransferase involved in sialyl Lewis $\mathrm{X}$ biosynthesis. ${ }^{37)}$

A subpopulation of activated lymphocytes expresses the active forms of CD44 and the $\beta 1$ integrin, VLA-4. Similar to selectins, CD44 is a carbohydrate-binding protein. In contrast to L-selectin, however, CD44 is expressed on naive lymphocytes as an inactive form lacking ligand-binding activity, and is converted to an active form with ligand-binding activity after lymphocyte activation. The mechanisms for CD44 activation are still controversial. Reports have indicated that (i) CD44 is negatively regulated by the addition of sialic acid on CD $44{ }^{38)}$ (ii) association with the cytoskeleton is critical for CD44's ligand-binding activity, ${ }^{39)}$ and (iii) sulfation of CD44 enhances its ligand-binding activity. ${ }^{40)}$ In addition to a wellknown ligand, hyaluronic acid (HA), ${ }^{41)}$ we found that the CSPG proteoglycans versican ${ }^{42,43)}$ and aggrecan ${ }^{44)}$ also function as ligands for CD44. It is also reported that CSPG serglycin functions as a CD44 ligand. ${ }^{45)}$ In vitro rolling assays revealed that $\mathrm{CD} 44-\mathrm{HA}^{46}$ ) and $\mathrm{CD} 44-\mathrm{CS}^{47)}$ interactions mediate lymphocyte rolling. Therefore, CD44 may function as a rolling receptor in the process by which L-selectin ${ }^{-}$/active CD $44^{+}$lymphocytes infiltrate the sites of inflammation by interacting with these ligands.

\section{FUTURE PERSPECTIVE}

HEV-like vessels that react with the MECA-79 antibody are induced in various chronic inflammatory sites. ${ }^{48)}$ However, the physiological role of the MECA-79 epitope expressed in these specialized blood vessels is unclear, except for the demonstration that MECA-79 has a significant therapeutic effect in a sheep model of asthma. ${ }^{49)}$ GlcNAc6ST-1 and -2 double-deficient mice, which completely lack the MECA-79 epitope, will be useful for assessing the function of this sulfated glycan at sites of chronic inflammation, such as the pancreas and salivary glands of NOD mice, ${ }^{50,51)}$ the hyperplastic thymus of AKR mice, ${ }^{52)}$ the inflamed joints of rheumatoid arthritis, ${ }^{53)}$ and Helicobacter pylori-induced inflammation. ${ }^{54)}$

Our studies using GlcNAc6ST-1 and -2 double-deficient mice have shown a link between carbohydrate structural changes and the alteration of lymphocyte trafficking under physiological conditions. Since carbohydrates have recently 
been implicated in immunologic function in a number of studies, I believe that studies showing links between carbohydrate structure and function will become increasingly important in this field.

Our group has shown that CS B and CS E inhibit chemokine signals. ${ }^{33-35)}$ We also showed that these glycosaminoglycans inhibit the binding of L-selectin to its ligands. ${ }^{33,43)}$ Therefore, these glycosaminoglycans might be useful for inhibiting both the selectin-mediated rolling interaction and the chemokine-induced signals in the process of lymphocyte homing as well as leukocyte infiltration to the sites of inflammation, which may be of clinical importance for suppressing autoimmune as well as inflammatory reactions.

Acknowledgements I would like to thank Professors Hiroyoshi Ariga (Hokkaido University) and Naoto Oku (University of Shizuoka) for providing me the opportunity to write this review. I also thank Professor Minoru Fukuda (The Burnham Institute) for giving me the chance to work on sulfotransferase double-deficient mice. The work presented here was supported in part by NIH grant P01CA71932, a Research Fellowship from the Uehara Memorial Foundation, Japan, and Grants-in-Aid from the Ministry of Education, Culture, Sports, Science and Technology, Japan.

\section{REFERENCES}

1) Springer T. A., Cell, 76, 301-314 (1994).

2) von Andrian U. H., Hasslen S. R., Nelson R. D., Erlandsen S. L., Butcher E. C., Cell, 82, 989-999 (1995).

3) Arbonés M. L., Ord D. C., Ley K., Ratech H., Maynard-Curry C., Otten G., Capon D. J., Tedder T. F., Immunity, 1, 247-260 (1994).

4) Lasky L. A., Singer M. S., Dowbenko D., Imai Y., Henzel W. J., Grimley C., Fennie C., Gillett N., Watson S. R., Rosen S. D., Cell, 69, 927-938 (1992).

5) Baumhueter S., Singer M. S., Henzel W., Hemmerich S., Renz M., Rosen S. D., Lasky L. A., Science, 262, 436 438 (1993).

6) Sassetti C., Tangemann K., Singer M. S., Kershaw D. B., Rosen S. D., J. Exp. Med., 187, 1965-1975 (1998).

7) Hemmerich S., Butcher E. C., Rosen S. D., J. Exp. Med., 180, 22192226 (1994).

8) Umemoto E., Tanaka T., Kanda H., Jin S., Tohya K., Otani K., Matsutani T., Matsumoto M., Ebisuno Y., Jang M. H., Fukuda M., Hirata T., Miyasaka M., J. Exp. Med., 203, 1603-1614 (2006).

9) Yeh J. C., Hiraoka N., Petryniak B., Nakayama J., Ellies L. G., Rabuka D., Hindsgaul O., Marth J. D., Lowe J. B., Fukuda M., Cell, 105, 957969 (2001).

10) Streeter P. R., Rouse B. T. N., Butcher E. C., J. Cell Biol., 107, 18531862 (1988).

11) Rosen S. D., Singer M. S., Yednock T. A., Stoolman, L. M., Science, 228, 1005-1007 (1985).

12) Homeister J. W., Thall A. D., Petryniak B., Maly P., Rogers C. E., Smith P. L., Kelly R. J., Gersten K. M., Askari S. W., Cheng G., Smithson G., Marks R. M., Misra A. K., Hindsgaul O., von Andrian U. H., Lowe J. B., Immunity, 15, 115-126 (2001).

13) Imai Y., Lasky L. A., Rosen S. D., Nature (London), 361, 555-557 (1993).

14) Hiraoka N., Kawashima H., Petryniak B., Nakayama J., Mitoma J., Marth J. D., Lowe J. B., Fukuda M., J. Biol. Chem., 279, 3058-3067 (2004).

15) Hemmerich S., Bistrup A., Singer M. S., van Zante A., Lee J. K., Tsay D., Peters M., Carminati J. L., Brennan T. J., Carver-Moore K., Leviten M., Fuentes M. E., Ruddle N. H., Rosen S. D., Immunity, 15, $237-$ 247 (2001)

16) Kawashima H., Petryniak B., Hiraoka N., Mitoma J., Huckaby V., Nakayama J.,Uchimura K., Kadomatsu K., Muramatsu T., Lowe J. B., Fukuda M., Nat. Immunol., 6, 1096-1104 (2005).
17) Uchimura K., Gauguet J.-M., Singer M. S., Tsay D., Kannagi R., Muramatsu T., von Andrian U. H., Rosen S. D., Nat. Immunol., 6, 11051113 (2005).

18) Uchimura K., Kadomatsu K., El-Fasakhany F. M., Singer M. S., Izawa M., Kannagi R., Takeda N., Rosen S. D., Muramatsu T., J. Biol. Chem., 279, 35001-35008 (2004).

19) Warnock R. A., Askari S., Butcher E. C., von Andrian U. H., J. Exp. Med., 187, 205-216 (1998).

20) Gunn M. D., Tangemann K., Tam C., Cyster J. G., Rosen S. D., Williams L. T., Proc. Natl. Acad. Sci. U.S.A., 95, 258-263 (1998).

21) Luther S. A., Tang H. L., Hyman P. L., Farr A. G., Cyster J. G., Proc. Natl. Acad. Sci. U.S.A., 97, 12694-12699 (2000).

22) Nakano H., Gunn M. D., J. Immunol., 166, 361-369 (2001).

23) Forster R., Schubel A., Breitfeld D., Kremmer E., Renner-Muller I., Wolf E., Lipp M., Cell, 99, 23-33 (1999)

24) Bernfield M., Gotte M., Park P. W., Reizes O., Fitzgerald M. L., Lincecum J., Zako M., Annu. Rev. Biochem., 68, 729-777 (1999).

25) Tanaka Y., Adams D. H., Hubscher S., Hirano H., Siebenlist U., Shaw S., Nature (London), 361, 79-82 (1993).

26) Tanaka Y., Fujii K., Hubscher S., Aso M., Takazawa A., Saito K., Ota T., Eto S., Arthritis Rheum., 41, 1365-1377 (1998).

27) Gilat D., Hershkoviz R., Mekori Y. A., Vlodavsky I., Lider O., J. Immunol., 153, 4899-4906 (1994).

28) Tanaka Y., Kimata K., Wake A., Mine S., Morimoto I., Yamakawa N., Habuchi H., Ashikari S., Yamamoto H., Sakurai K., Yoshida K., Suzuki S., Eto S., J. Exp. Med., 184, 1987-1997 (1996).

29) Kawashima H., Watanabe N., Hirose M., Sun X., Atarashi K., Kimura T., Shikata K., Matsuda M., Ogawa D., Heljasvaara R., Rehn M., Pihlajaniemi T., Miyasaka M., J. Biol. Chem., 278, 13069-13076 (2003).

30) Wang L., Fuster M., Sriramarao P., Esko J. D., Nat. Immunol., 6, $902-$ 910 (2005).

31) Oravecz T., Pall M., Wang J., Roderiquez G., Ditto M., Norcross M. A., J. Immunol., 159, 4587-4592 (1997).

32) Wolff E. A., Greenfield B., Taub D. D., Murphy W. J., Bennett K. L., Aruffo A., J. Biol. Chem., 274, 2518-2524 (1999).

33) Kawashima H., Atarashi K., Hirose M., Hirose J., Yamada S., Sugahara K., Miyasaka M., J. Biol. Chem., 277, 12921-12930 (2002).

34) Hirose J., Kawashima H., Yoshie O., Tashiro K., Miyasaka M., J. Biol. Chem., 276, 5228-5234 (2001).

35) Hirose J., Kawashima H., Swope-Willis M., Springer T. A., Hasegawa H., Yoshie O., Miyasaka M., Biochim. Biophys. Acta, 1571, 219-224 (2002).

36) Fuhlbrigge R. C., Kieffer J. D., Armerding D., Kupper T. S., Nature (London), 389, 978-981 (1997).

37) Wagers A. J., Waters C. M., Stoolman L. M., Kansas G. S., J. Exp. Med., 188, 2225-2231 (1998).

38) Skelton T. P., Zeng C., Nocks A., Stamenkovic I., J. Cell Biol., 140, $431-446$ (1998).

39) Perschl A., Lesley J., English N., Trowbridge I., Hyman R., Eur. J. Immunol., 25, 495-501 (1995).

40) Maiti A., Maki G., Johnson, P., Science, 282, 941—943 (1998)

41) Aruffo A., Stamenkovic I., Melnick M., Underhill C. B., Seed B., Cell, 61, 1303-1313 (1990).

42) Kawashima H., Li Y.-F., Watanabe N., Hirose J., Hirose M., Miyasaka M., Int. Immunol., 11, 393- 405 (1999).

43) Kawashima H., Hirose M., Hirose J., Nagakubo D., Plaas A. H. K., Miyasaka M., J. Biol. Chem., 275, 35448-35456 (2000).

44) Fujimoto T., Kawashima H., Tanaka T., Hirose M., Toyama-Sorimachi N., Matsuzawa Y., Miyasaka M., Int. Immunol., 13, 359-366 (2001).

45) Toyama-Sorimachi N., Sorimachi H., Tobita Y., Kitamura F., Yagita H., Suzuki K., Miyasaka M., J. Biol. Chem., 270, 7437-7444 (1995).

46) DeGrendele H. C., Estess P., Picker L. J., Siegelman M. H., J. Exp. Med., 183, 1119-1130 (1996).

47) Murai T., Sougawa N., Kawashima H., Yamaguchi K., Miyasaka M., Immunol. Lett., 93, 163-170 (2004).

48) Rosen S. D., Am. J. Pathol., 155, 1013-1020 (1999).

49) Rosen S. D., Tsay D., Singer M. S., Hemmerich S., Abraham W. M., Am. J. Pathol., 166, 935-944 (2005).

50) Hanninen A., Taylor C., Streeter P. R., Stark L. S., Sarte J. M., Shizuru J. A., Simell O., Michie S. A., J. Clin. Invest., 92, 2509-2515 (1993).

51) Faveeuw C., Gagnerault M.-C., Lepault F., J. Immunol., 152, 59695978 (1994).

52) Michie S. A., Streeter P. R., Butcher E. C., Rouse R. V., Am. J. Pathol., 147, 412-421 (1995). 
53) Michie S. A., Streeter P. R., Bolt P. A., Butcher E. C., Picker L. J., Am J. Pathol., 143, 1688-1698 (1993).

54) Kobayashi M., Mitoma J., Nakamura N., Katsuyama T., Nakayama J., Fukuda M., Proc. Natl. Acad. Sci. U.S.A., 101, 17807-17812 (2004).

55) Akama T. O., Nishida K., Nakayama J., Watanabe H., Ozaki K., Nakamura T., Dota A., Kawasaki S., Inoue Y., Maeda N., Yamamoto S., Fu- jiwara T., Thonar E. J., Shimomura Y., Kinoshita S., Tanigami A., Fukuda M. N., Nat. Genet., 26, 237-241 (2000).

56) Bhakta S., Bartes A., Bowman K. G., Kao W. M., Polsky I., Lee J. K., Cook B. N., Bruehl R. E., Rosen S. D., Bertozzi C. R., Hemmerich S., J. Biol. Chem., 275, 40226-40234 (2000). 